\title{
Evaluation of factors influencing arterial Doppler waveforms in an in vitro flow phantom
}

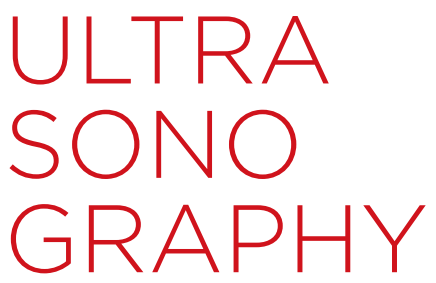

\author{
Chang Kyu Sung ${ }^{1}$, Kyoung Ho Lee ${ }^{2}$, Seung Hyup Kim³ \\ 1 Department of Radiology, SMG-SNU Boramae Medical Center, Seoul National University \\ College of Medicine, Seoul; ${ }^{2}$ Department of Radiology, Seoul National University Bundang \\ Hospital, Seoul National University College of Medicine, Seongnam; ${ }^{3}$ Department of \\ Radiology and the Institute of Radiation Medicine, Seoul National University Hospital, Seoul \\ National University College of Medicine, Seoul, Korea
}

Purpose: The aim of this study was to investigate factors that influence arterial Doppler waveforms in an in vitro phantom to provide a more accurate and comprehensive explanation of the Doppler signal.

Methods: A flow model was created using a pulsatile artificial heart, rubber or polyethylene tubes, a water tank, and a glass tube. Spectral Doppler tracings were obtained in multiple combinations of compliance, resistance, and pulse rate. Peak systolic velocity, minimum diastolic velocity, resistive index (RI), pulsatility index, early systolic acceleration time, and acceleration index were measured. On the basis of these measurements, the influences of the variables on the Doppler waveforms were analyzed.

Results: With increasing distal resistance, the RI increased in a relatively linear relationship. With increasing proximal resistance, the RI decreased. The pulsus tardus and parvus phenomenon was observed with a small acceleration index in the model with a higher grade of stenosis. An increase in the distal resistance masked the pulsus tardus and parvus phenomenon by increasing the acceleration index. Although this phenomenon occurred independently of compliance, changes in the compliance of proximal or distal tubes caused significant changes in the Doppler waveform. There was a reverse relationship between the RI and the pulse rate.

Conclusion: Resistance and compliance can alter the Doppler waveforms independently. The pulse rate is an extrinsic factor that also influences the RI. The compliance and distal resistance, as well as proximal resistance, influence the pulsus tardus and parvus phenomenon.

Keywords: Renal artery; Ultrasonography, Doppler; Phantoms, imaging

\section{Introduction}

Doppler ultrasonography is a relatively simple and accurate method for determining the existence and the direction of the blood flow and diagnosing various diseases that influence the blood flow.

\section{ORIGINAL ARTICLE}

https://doi.org/10.14366/usg. 15055 pISSN: 2288-5919 • elSSN: 2288-5943 Ultrasonography 2017;36:39-52

Received: Septmeber 15, 2015

Revised: July 4, 2016

Accepted: July 7, 2016

Correspondence to:

Seung Hyup Kim, MD, Department of Radiology and the Institute of Radiation Medicine, Seoul National University Hospital, Seoul National University College of Medicine, 101 Daehak-ro, Jongno-gu, Seoul 03080, Korea

Tel. +82-2-2072-2510

Fax. +82-2-743-6385

E-mail: kimsh@radcom.snu.ac.kr

\begin{abstract}
This is an Open Access article distributed under the terms of the Creative Commons Attribution NonCommercial License (http://creativecommons.org/ licenses/by-nc/3.0/) which permits unrestricted noncommercial use, distribution, and reproduction in any medium, provided the original work is properly cited.
\end{abstract}

Copyright @ 2017 Korean Society of Ultrasound in Medicine (KSUM)

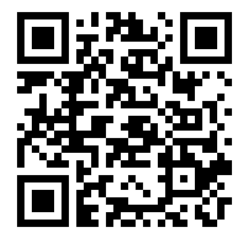

How to cite this article:

Sung CK, Lee KH, Kim SH. Evaluation of factors influencing arterial Doppler waveforms in an in vitro flow phantom. Ultrasonography. 2017 Jan;36(1):39-52. 
It involves analyzing the difference within the frequency of the Doppler waveforms of the bloodstream that may provide functional information about the stenosis in upper blood vessels and the change in the resistance in the distal blood vessels. Among several parameters of a Doppler waveform analysis, the resistive index (RI) has been widely used for supporting diagnostic and therapeutic procedures. Its value has been confirmed in various clinical settings of renal diseases, including acute tubular necrosis, obstructive or medical nephropathy, atherosclerotic renovascular disease, and renal transplant dysfunction [1-7]. However, there is a lack of RI specificity in the evaluation of intrinsic renal disease, and several studies published to date have reported conflicting results about the utility of RI [8-10]. The lack of consensus on the utility of renal Doppler may be attributed to the limited understanding of Doppler waveforms in the evaluation of the changes in renal status and the pathophysiology of renal disease. The complex interaction between renal vascular resistance and compliance partly explains the failure of Doppler sonography to consistently differentiate among types of intrinsic renal disease [11].

Several studies have evaluated the usefulness of Doppler ultrasonography in detecting renal artery stenosis $[12,13]$. Hemodynamically significant stenosis of the renal artery causes changes in the shape of the time-velocity waveform in the downstream arterial network. It generally refers to delayed or prolonged early systolic acceleration and diminished amplitude and rounding of the systolic peak, which has been described as the classic signs of pulsus tardus and parvus (PTP). However, the cause of this phenomenon remains unclear. To analyze the possible factors and their relationships and interactions in Doppler signals, we constructed a renal blood flow phantom that showed a lowresistance waveform in a complete closed circuit corresponding to unilateral kidneys on the basis of the pulsating blood flow model of Chung et al. [14] with an artificial heart pump. The aim of this study was to investigate factors that influence renal arterial Doppler waveforms in a renal flow phantom with a focus on the RI and the phenomenon of PTP in order to provide a more accurate and comprehensive explanation of the Doppler signal.

\section{Materials and Methods}

Institutional Review Board and Institutional Animal Care and Use Committee approvals were not required because this study did not use any human or animal data.

\section{Research Materials}

A closed-circuit in vitro blood flow model was constructed from glass tubes, a water tank, rubber tubes, polyethylene tubes, and the artificial heart of an electrohydraulic ventricular assist device controlled by a computer (Fig. 1). The artificial heart model was the Korean-type total artificial heart (Kor-TAH) developed by the Department of Biomedical Engineering of Seoul National University Hospital. This model controls the stroke volume, the heartbeat, and the compressed waveforms through six control factors, namely the left stroke angle, right stroke angle, left velocity, right velocity, left break time, and right break time, which has similar pressure mechanisms that can produce a pulsatile blood flow similar to that produced by an in vivo heart. Through such preliminary experiments, the control variables for the artificial heart were fixed as follows: left stroke angle, $30^{\circ}$; right stroke angle, $5^{\circ}$; left velocity, $20^{\circ} / \mathrm{sec}$; right velocity, $10 \% \mathrm{sec}$, left break time, $0 \mathrm{msec}$; and right break time, 30 msec, which remained unchanged throughout the experiment.

In order to simulate the blood vessels, rubber tubes and polyethylene tubes (length, $0.5 \mathrm{~m}, 1 \mathrm{~m}$, and $2 \mathrm{~m}$ ) were used, where two specific materials were chosen to assess the influence of a change in compliance. The external and internal diameters of the tubes were $16.6 \mathrm{~mm}$ and $11.5 \mathrm{~mm}$, respectively. The ultrasound could not pass well through these two types of tubes; therefore, glass tubes were placed in the middle of the circuit, which made it possible to conduct the Doppler ultrasound study. The measurements of the glass tube were as follows: length, $30 \mathrm{~cm}$; external diameter, $15 \mathrm{~mm}$; internal diameter, $12 \mathrm{~mm}$; and thickness, $1.5 \mathrm{~mm}$. The glass tube was installed in a plastic support device filled with water for the ultrasound to pass through easily. The part of the glass tube that stood outside of the plastic support device was stopped in order to avoid water leakage, and both ends of the glass tube were connected to tubes of different lengths and materials, namely rubber and polyethylene, so that the compliance of both proximal and distal blood vessels of the examined site could be checked through a Doppler ultrasound study. At the end of the distal tubes, a stopcock controlled the degree of openness, which influenced the resistance level in the distal vessels and corresponded to the resistance in the peripheral vessels such as the arterioles, which provide significant resistance to the blood flow and serve as a major determinant of the blood pressure in the human body. The blood that flowed through the stopcock placed at the very end of the distal tubes was first collected in a water tank that corresponded to the capillary network and was subsequently pumped into the artificial heart by a small pump.

In order to mock the viscosity of the blood at $20^{\circ} \mathrm{C}, 350 \mathrm{~mL}$ of glycerol was added per liter of water [15]. To achieve an adequate Doppler signal, $1 \mathrm{~g}$ of corn starch was added per liter of water for the scattering effect; this mixture was constantly stirred in the water tank in order to maintain an equal distribution [12]. 


\section{Research Method}

As shown in Fig. 1, the closed circuit was designed in the following order: artificial heart model, rubber or polyethylene tube, glass tube, rubber or polyethylene tube, stopcock, water tank, polyethylene tube, and artificial heart model. This design simulated a unilateral renal vascular flow model. By using a computer system, we manipulated control variables and assessed the Doppler waveforms to find the conditions under which the triphasic waves were transformed into waveforms that resembled the ski slope form, like that of the renal blood flow. A spectral Doppler waveform was obtained by switching the rubber and polyethylene tubes at the sites where the glass tube was connected, while the control variables of the artificial heart were kept fixed, in order to examine the influence of the change in the compliance of the blood vessels. For both rubber and polyethylene tubes, two of each of 0.5-m-, 1-m-, and 2-m-long tubes were used, which made a total of 36 combinations possible. The resistance effects were evaluated using a vascular model, made out of either rubber $(2 \mathrm{H}-2 \mathrm{H})$ or polyethylene tubes $(2 \mathrm{~L}-2 \mathrm{~L})$, in which the proximal and distal parts were $2 \mathrm{~m}$ long, respectively. The effects of distal resistance were assessed by changing the stopcock angles (either $0^{\circ}, 30^{\circ}$, or $60^{\circ}$ ) located at the end of the distal tube. In contrast, to assess the effects of proximal resistance, small tubes with four different diameters and two different tube lengths (1.5 $\mathrm{cm}$ and $3 \mathrm{~cm}$ ) were coaxially inserted into a rubber tube (internal diameter, $11.5 \mathrm{~mm}$ ) to make a four-degree stenosis model. All stenoses were graded in one of the following five groups: grade 0 (0\% diameter stenosis), grade 1 (21\% diameter stenosis), grade 2 (45\% diameter stenosis), grade 3 (67\% diameter stenosis), and grade 4 (77\% diameter stenosis) (Fig. 1C). In order to examine the influence of the change in the heart beat, the left break time was varied as $0,10,30,50,70,90,110$, and 200 milliseconds, while all the other variables were kept fixed during the Doppler examination.

Spectral Doppler sonography was conducted under the same condition by using a 7-MHz linear transducer, and one researcher performed the examination in order to reduce the inter-observer variation. In the Doppler frequency shift waveforms gathered through the spectral Doppler examination, the peak systolic velocity (PSV), minimum diastolic velocity (MDV), RI, pulsatility index (PI),

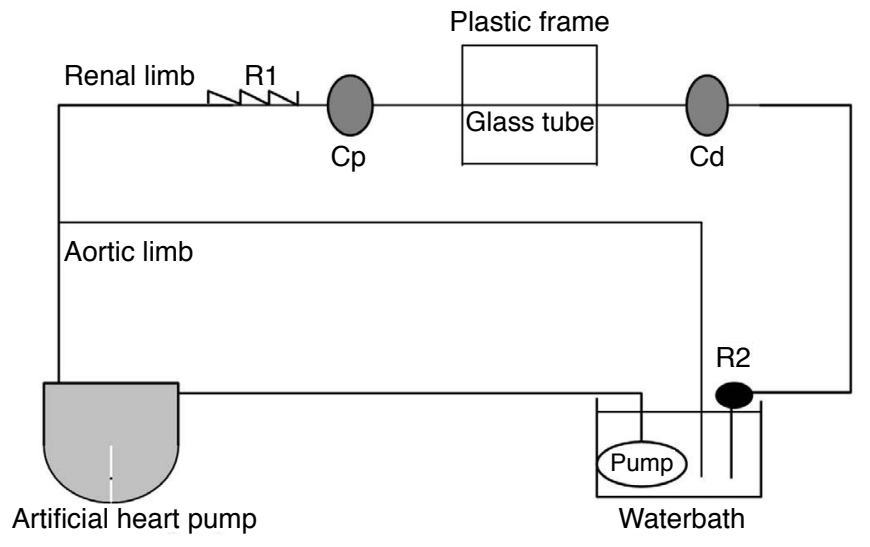

A

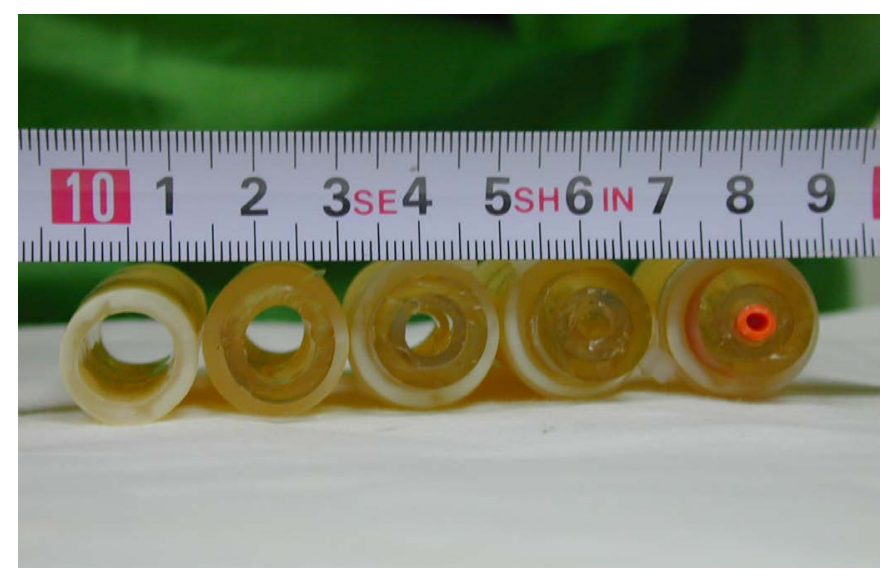

C

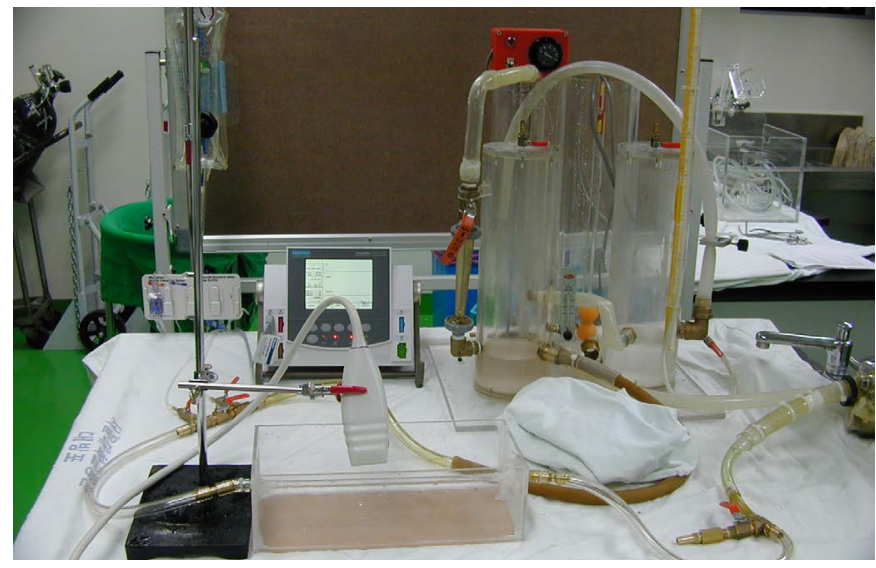

B

Fig. 1. Schematic (A) and picture (B) of the experiment setup and a photograph (C) of the stenosis model (grade 0 to grade 4 , from left to right).

A, B. The in vitro flow model was made into a closed circuit by using glass tubes, a water tank, rubber tubes, polyethylene tubes, and an artificial heart. Cp, proximal compliance; Cd, distal compliance; R1, proximal stenotic segment (grade $0-4$ ); R2, one-way valve (stopcock) for distal resistance. C. Small tubes with four different diameters were coaxially inserted into a rubber tube (internal diameter, 11.5 $\mathrm{mm}$ ) to make a four-degree stenosis model. All stenoses were graded into five groups: grade 0 ( $0 \%$ diameter stenosis), grade 1 (21\% diameter stenosis), grade 2 (45\% diameter stenosis), grade 3 (67\% diameter stenosis), and grade 4 (77\% diameter stenosis). 
early systolic acceleration time (AT), and acceleration index (AI) were measured. The RI is equal to the value of the PSV with the MDV subtracted and then divided by the PSV; the PI refers to the PSV subtracted by the MDV divided by the mean velocity, which were easily calculated by the built-in software of the ultrasonic devices. The AT denotes the time interval between the beginning of systole and the early systolic compliance peak, and the Al represents the ratio of the AT to the PSV, which was also calculated by the software inside the ultrasonic device. Based on such measurements, the influences of the vessel compliance, resistance, and heart beat rate on the spectral Doppler waveform were analyzed with special attention to the influences on the RI and the phenomenon of PTP in order to provide a more accurate and comprehensive explanation of the Doppler signal.

For the statistical evaluation, a linear regression analysis was used and regression coefficients were compared with a one-way analysis of variance to determine whether the linear regression fits differed significantly; a P-value smaller than 0.05 was considered to indicate a statistically significant difference.

\section{Results}

Influence of the Changes in Compliance on the Parameters of the Spectral Doppler Waveforms in the Absence of Stenosis

The measurements are summarized in Table 1 and supplementary Table 1.

\section{Changes in the Doppler waveforms depending on the compliance}

In the combination of polyethylene tubes that had a lower compliance for both proximal and distal vessels, the spectral Doppler waveforms peaked in the early systole with a rapid increase until the second peak in an adjacent area, and slowly decreased until the end of the diastolic phase, which most resembled the waveforms of the renal vessels (Fig. 2A). When the polyethylene tubes were replaced by rubber tubes, which had a higher compliance, more complicated spectral Doppler waveforms were observed. The tendency depicted in various combinations in the proximal and distal vessels cannot be simplified; however, certain characteristics could be theorized as follows: in the case of lower compliance in the distal vessels,

Table 1. Summary of Doppler examinations for various combinations of compliance and tube length

\begin{tabular}{|c|c|c|c|c|c|c|c|}
\hline $\begin{array}{c}\text { Proximal } \\
\text { compliance level }\end{array}$ & $\begin{array}{c}\text { Distal compliance } \\
\text { level }\end{array}$ & PSV $(\mathrm{cm} / \mathrm{sec})$ & $\mathrm{MDV}(\mathrm{cm} / \mathrm{sec})$ & $\mathrm{RI}$ & $\mathrm{PI}$ & AT (msec) & $\mathrm{Al}\left(\mathrm{cm} / \mathrm{sec}^{2}\right)$ \\
\hline \multirow[t]{6}{*}{$\operatorname{Low}(0.5)$} & Low $(0.5)$ & 272.7 & -10.2 & 1.04 & 2.99 & 80 & $3,536.8$ \\
\hline & High (0.5) & 232.0 & -10.2 & 1.04 & 2.64 & 110 & $2,270.9$ \\
\hline & Low (1) & 234.5 & -7.6 & 1.03 & 2.77 & 90 & $2,634.0$ \\
\hline & High (1) & 211.6 & 22.9 & 0.89 & 1.52 & 90 & $2,124.2$ \\
\hline & $\operatorname{Low}(2)$ & 183.5 & 28.0 & 0.85 & 1.38 & 70 & $2,039.3$ \\
\hline & High (2) & 221.8 & 28.0 & 0.87 & 1.79 & 140 & $1,329.1$ \\
\hline \multirow[t]{6}{*}{ Low (1) } & Low (0.5) & 244.7 & -7.6 & 1.03 & 2.59 & 90 & $2,775.6$ \\
\hline & High (0.5) & 224.3 & 15.3 & 0.93 & 1.94 & 90 & $2,379.1$ \\
\hline & Low (1) & 211.6 & 5.1 & 0.98 & 1.80 & 110 & $1,853.8$ \\
\hline & High (1) & 191.2 & 25.5 & 0.87 & 1.45 & 70 & $2,330.6$ \\
\hline & $\operatorname{Low}(2)$ & 170.8 & 35.7 & 0.79 & 1.11 & 70 & $1,857.1$ \\
\hline & High (2) & 232.0 & 30.6 & 0.87 & 1.70 & 100 & $1,988.2$ \\
\hline \multirow[t]{6}{*}{ Low (2) } & Low (0.5) & 239.6 & 28.0 & 0.88 & 1.64 & 80 & $2,580.9$ \\
\hline & High (0.5) & 209.0 & 25.5 & 0.88 & 1.59 & 80 & $2,198.5$ \\
\hline & Low (1) & 201.4 & 35.7 & 0.82 & 1.56 & 70 & $2,476.1$ \\
\hline & High (1) & 181.0 & 38.2 & 0.79 & 1.33 & 80 & $1,752.5$ \\
\hline & $\operatorname{Low}(2)$ & 168.2 & 45.9 & 0.73 & 1.10 & 80 & $1,625.0$ \\
\hline & High (2) & 209.0 & 45.9 & 0.78 & 1.44 & 90 & $1,841.0$ \\
\hline
\end{tabular}

Numbers in parentheses indicate the length of the tube in meters. "Low" indicates a polyethylene tube with low compliance, and "high" indicates a rubber tube with relatively high compliance.

PSV, peak systolic velocity; MDV, minimum diastolic velocity; RI, resistive index; PI, pulsatility index; AT, acceleration time; Al, acceleration index. 
when the proximal vessel compliance is increased, the second peak after the early-systole peak was delayed, which may result in the formation of a triphasic waveform by the separation of the second peak from the first peak and the second peak in the diastole after showing a reversed flow (Fig. 2B). In the case of higher distal vessel compliance, we observed similar results but weaker changes as compared to the setting of lower distal vessel compliance when the proximal vessel compliance was increased (Fig. 2C). Therefore, similar to the triphasic waveforms in large arteries in the human body, the diphasic waveforms transformed into triphasic waveforms when the distal compliance was low and the proximal compliance was high. In the case of lower proximal vessel compliance, a more prominent late systolic peak was seen with increasing distal vessel compliance (Fig. 2D). In the case of higher proximal vessel compliance, higher distal vessel compliance resulted in slightly more diastolic flow (Fig. 2E).
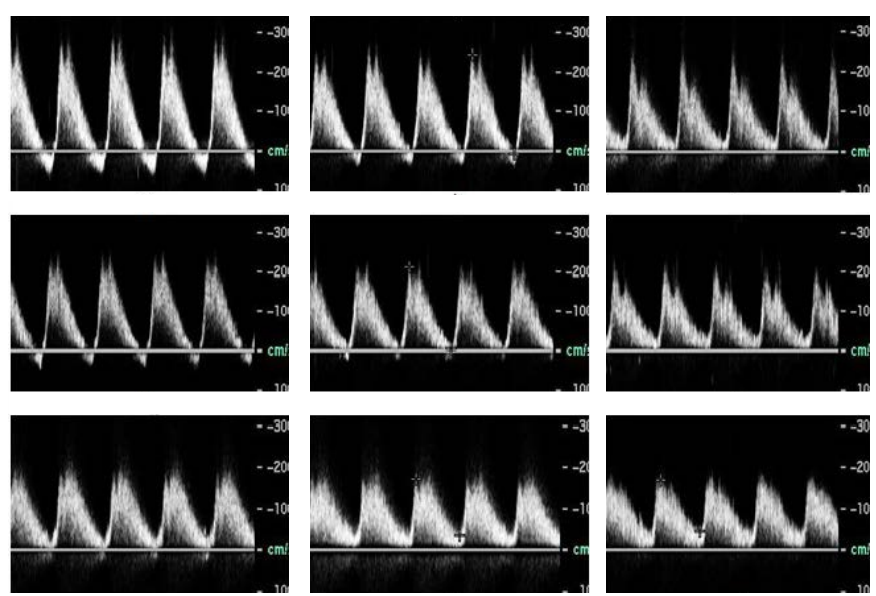

A

Fig. 2. Spectral Doppler waveforms for various compliance settings.

A. In the low-compliance model, all tubings are composed of polyethylene tubes. The top line denotes the waveforms in the settings with the same distal tube of the $0.5-\mathrm{m}$-long polyethylene tube (right, $0.5 \mathrm{~L}-0.5 \mathrm{~L}$; center, $1 \mathrm{~L}-0.5 \mathrm{~L}$; left, $2 \mathrm{~L}-0.5 \mathrm{~L}$ ). The middle line indicates the waveforms in the settings with the same distal tube of the 1-m-long polyethylene tube (right, $0.5 \mathrm{~L}-1 \mathrm{~L}$; center, $1 \mathrm{~L}-1 \mathrm{~L}$; left, $2 \mathrm{~L}-1 \mathrm{~L}$ ). Bottom line represents the waveforms in the settings with the same distal tube of the 2-m-long polyethylene tube (right, $0.5 \mathrm{~L}-2 \mathrm{~L}$; center, $1 \mathrm{~L}-2 \mathrm{~L}$; left, $2 \mathrm{~L}-2 \mathrm{~L})$. Each number refers to the length of the tube. The former denotes the length of the proximal tube, and the latter, that of the distal tube. "L" represents a low-compliance tube (polyethylene tube). In the combination of polyethylene tubes, which had a lower compliance for both proximal and distal vessels, the spectral Doppler waveforms peaked in the early-systole with a rapid increase until its second peak in an adjacent area, and slowly decreased until the end of the diastolic phase, which resembled most of the waveforms of renal vessels. B. In the settings with distal low compliance, distal tubings are composed of low compliance tubes (polyethylene tubes). Proximal tubings are composed of high-compliance tubes (rubber tubes). The top line denotes the waveforms in the settings with the same distal tube of the 0.5 -m-long polyethylene tube (right, $0.5 \mathrm{H}-0.5 \mathrm{~L}$; center, $1 \mathrm{H}-0.5 \mathrm{~L}$; left, $2 \mathrm{H}-0.5 \mathrm{~L}$ ). The middle line indicates the waveforms in the settings with the same distal tube of the 1-m-long polyethylene tube (right, $0.5 \mathrm{H}-1 \mathrm{~L}$; center, $1 \mathrm{H}-1 \mathrm{~L}$; left, $2 \mathrm{H}-1 \mathrm{~L}$ ). The bottom line represents the waveforms in the settings with the same distal tube of the 2-m-long polyethylene tube (right, $0.5 \mathrm{H}-2 \mathrm{~L}$; center, $1 \mathrm{H}-2 \mathrm{~L}$; left, $2 \mathrm{H}-2 \mathrm{~L}$ ). " $\mathrm{H}$ " represents a high-compliance tube (rubber tube). In the case of lower compliance in the distal vessels, when the proximal vessel compliance is increased, the second peak after the early-systole peak was delayed, which may result in the formation of a triphasic waveform by the separation of the second peak from the first peak and the second peak in the diastole after showing a reversed flow.

e-ultrasonography.org

Ultrasonography 36(1), January 2017 
when the compliance of the proximal tube was lower. However, in some cases, contradicting results were observed; therefore, a fixed correlation was impossible (Fig. 3C, D). With the proximal tube fixed, when the difference in the RI between the rubber and
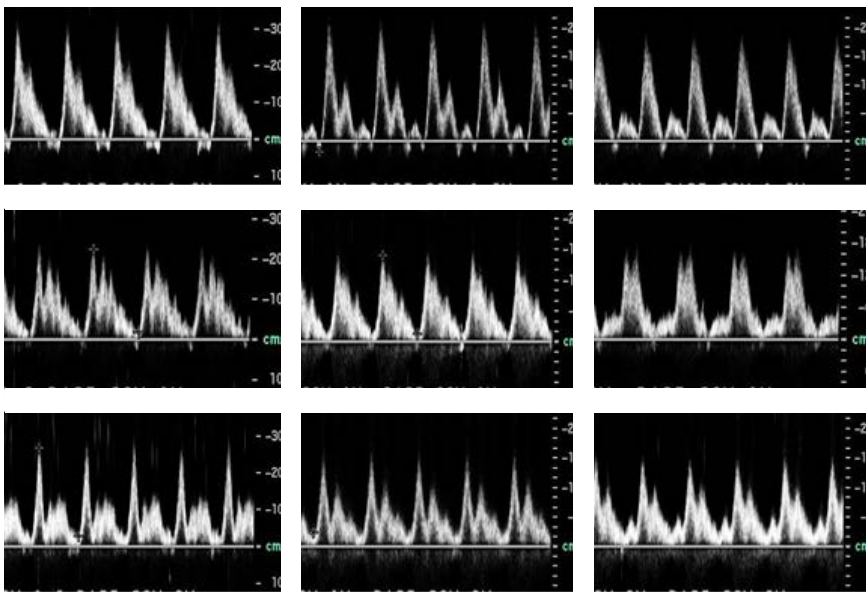

C
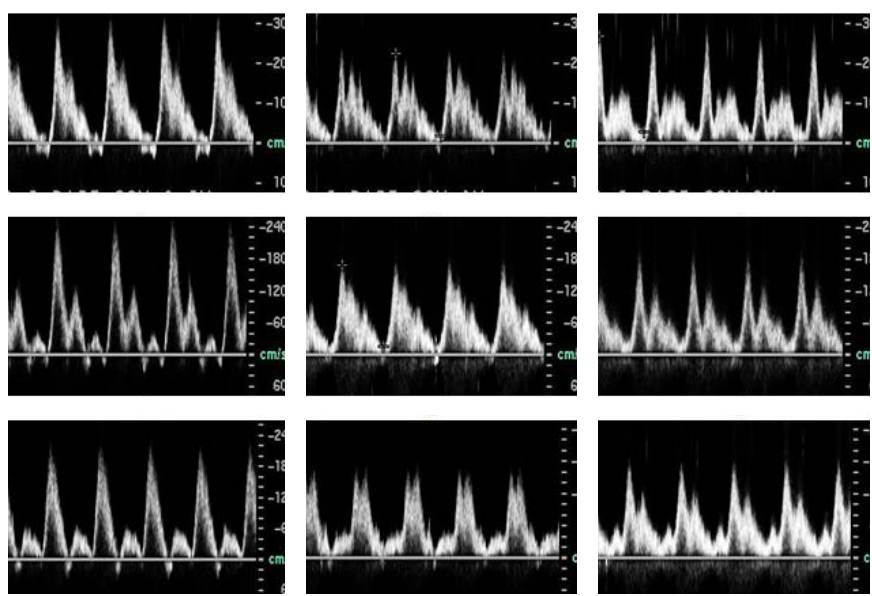
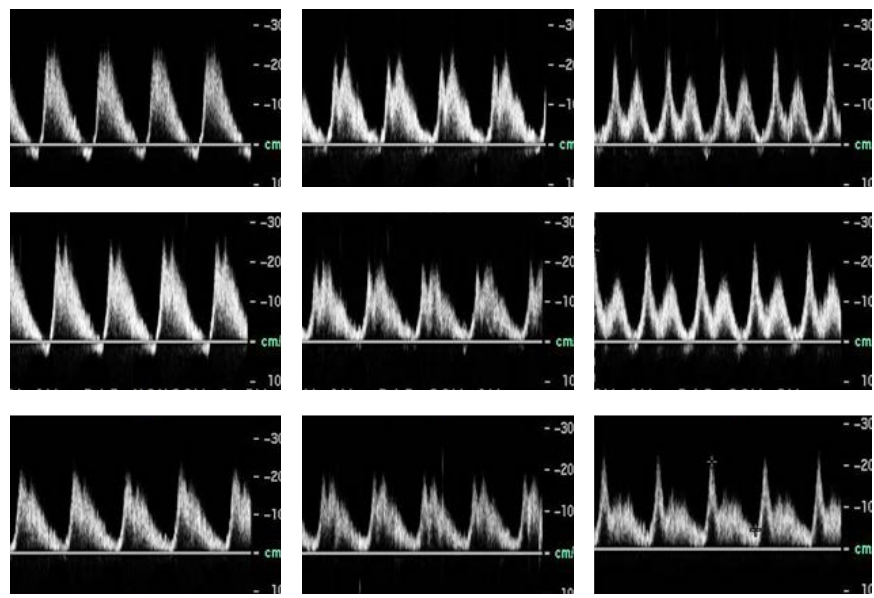

D

\section{$\mathrm{E}$}

C. In the settings with a distal high compliance, all pieces of tubing are composed of high-compliance tubes (rubber tubes). The top line indicates the waveforms in the settings with the same distal tube of the 0.5 -m-long rubber tube (right, $0.5 \mathrm{H}-0.5 \mathrm{H}$; center, $1 \mathrm{H}-0.5 \mathrm{H}$; left, $2 \mathrm{H}-0.5 \mathrm{H}$ ). The middle line represents the waveforms in the settings with the same distal tube of the 1-m-long rubber tube (right, $0.5 \mathrm{H}-$ $1 \mathrm{H}$; center, $1 \mathrm{H}-1 \mathrm{H}$; left, $2 \mathrm{H}-1 \mathrm{H}$ ). The bottom line denotes the waveforms in the settings with the same distal tube of the 2-m-long rubber tube (right, $0.5 \mathrm{H}-2 \mathrm{H}$; center, $1 \mathrm{H}-2 \mathrm{H}$; left, $2 \mathrm{H}-2 \mathrm{H}$ ). In the case of higher distal vessel compliance, similar results were obtained, but the changers were weaker as compared to the setting of the lower distal vessel compliance when the proximal vessel compliance is increased. D. In the settings with a proximal low compliance, proximal tubings are composed of low-compliance tubes (polyethylene tubes). Distal tubings are composed of high-compliance tubes (rubber tubes). Top line indicates the waveforms in the settings with the same proximal tube of the 0.5 -m-long polyethylene tube (right, $0.5 \mathrm{~L}-0.5 \mathrm{H}$; center, $0.5 \mathrm{~L}-1 \mathrm{H}$; left, $0.5 \mathrm{~L}-2 \mathrm{H}$ ). Middle line indicates the waveforms in the settings with the same proximal tube of the 1 -m-long polyethylene tube (right, $1 \mathrm{~L}-0.5 \mathrm{H}$; center, $1 \mathrm{~L}-1 \mathrm{H}$; left, $1 \mathrm{~L}-2 \mathrm{H}$ ). Bottom line represents the waveforms in the settings with the same proximal tube of the 2-m-long polyethylene tube (right, $2 \mathrm{~L}-0.5 \mathrm{H}$; center, $2 \mathrm{~L}-1 \mathrm{H}$; left, $2 \mathrm{~L}-2 \mathrm{H}$ ). In the case of lower proximal vessel compliance, a more prominent late systolic peak was seen with increasing distal vessel compliance. E. In the settings with proximal high compliance, all pieces of tubing are composed of high-compliance tubes (rubber tubes). The top line indicates the waveforms in the settings with the same proximal tube of the 0.5 -m-long rubber tube (right, $0.5 \mathrm{H}-0.5 \mathrm{H}$; center, $0.5 \mathrm{H}-1 \mathrm{H}$; left, $0.5 \mathrm{H}-$ $2 \mathrm{H}$ ). The middle line represents the waveforms in the settings with the same proximal tube of 1 -m-long rubber tube (right, $1 \mathrm{H}-0.5 \mathrm{H}$; center, $1 \mathrm{H}-0.5 \mathrm{H}$; left, $1 \mathrm{H}-0.5 \mathrm{H}$ ). Bottom line represents the waveforms in the settings with the same proximal tube of the 2-m-long rubber tube (tight, $2 \mathrm{H}-0.5 \mathrm{H}$; center, $2 \mathrm{H}-1 \mathrm{H}$; left, $2 \mathrm{H}-2 \mathrm{H}$ ). In the case of higher proximal vessel compliance, higher distal vessel compliance resulted in slightly more diastolic flow. 


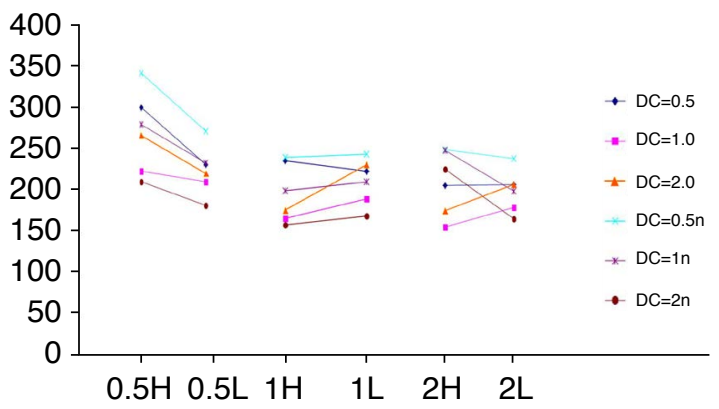

A

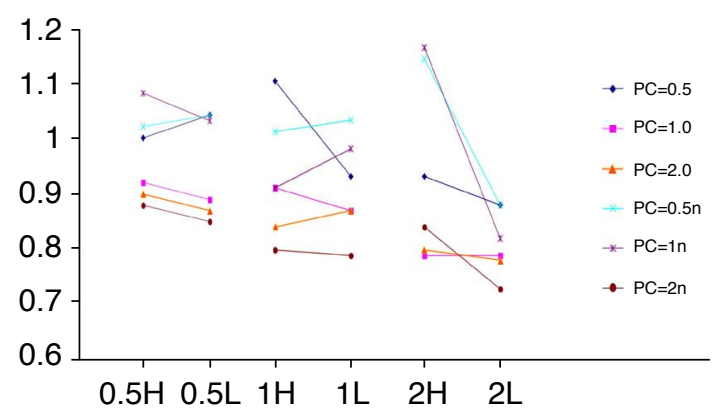

C

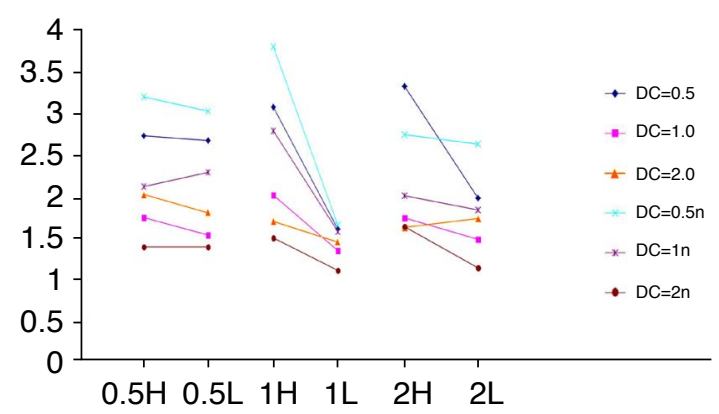

$E$

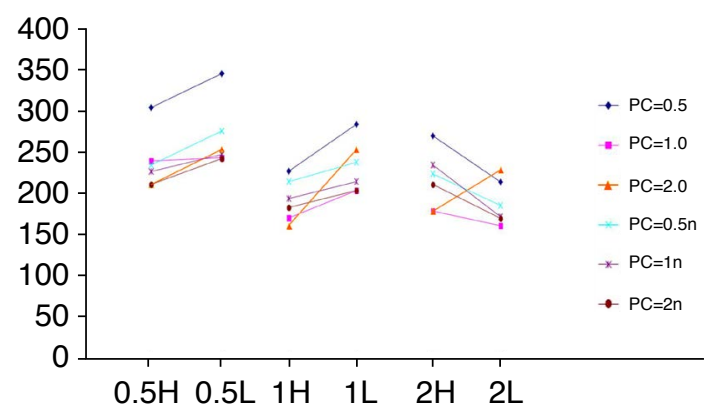

B

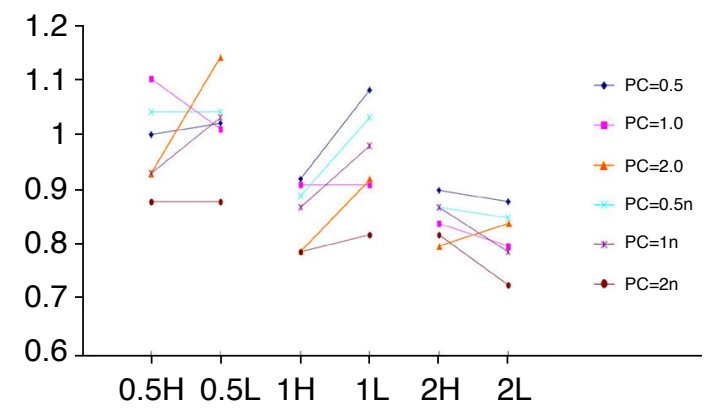

D

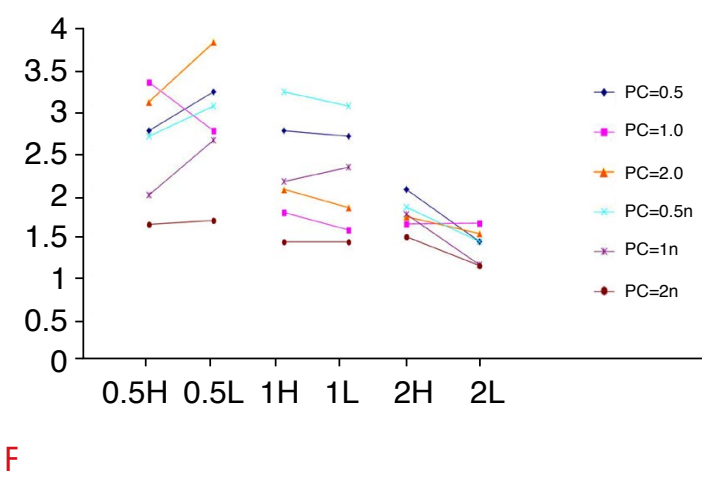

Fig. 3. Graph of peak systolic velocity (PSV), resistive index (RI), and pulsatility index (PI) for different compliance models.

A, B. Among graphs of PSV for different compliance models, panel A shows the comparison of PSV $(\mathrm{cm} / \mathrm{sec})$ for different proximal compliance in each distal tube. Panel B shows the comparison of PSV for different distal compliance in each proximal tube. The comparisons were made between rubber and polyethylene tubes of same length. The PSV did not show any consistent tendency when analyzed with different compliance combinations with the same length, in both distal and proximal vessel compliance. " $\mathrm{H}$ " represents a high-compliance tube (rubber tube). " $L$ " or " $n$ " represents a low-compliance tube (polyethylene tube). DC, distal compliance; PC, proximal compliance. C, D. Among the graphs of RI for different compliance models, panel C shows the comparison of the RI for different proximal compliance in each distal tube. Panel D shows the comparison of the RI for different distal compliance in each proximal tube. The comparisons were made between rubber and polyethylene tubes of the same length. The lower the compliance of the proximal tube, the smaller was the RI. However, in some cases, contradictory results were observed. Many cases showed that the RI was lower when the compliance of the distal tube was lower, but contradictory results were also observed. Thus, there was no correlation between the proximal or distal tube compliance and RI $(P>0.05)$. E, F. Among the graphs of PI for different compliance models, panel E shows the comparison of PI for different proximal compliance in each distal tube. Panel F shows the comparison of pulsatility index for different distal compliance in each proximal tube. The comparisons were made between rubber and polyethylene tubes of the same length. In distal tubes, there were no significant changes in the PI depending on the tube compliances, but in proximal tubes, higher compliances resulted in a higher PI rather than a lower tube compliance. 
the polyethylene tubes as a distal vessel was compared, many cases showed that the RI was lower when the compliance of the distal tube was lower, but contradicting results were also observed. Thus, there was no correlation between the proximal or distal tube compliance and RI $(\mathrm{P}>0.05)$.

\section{Influence of vessel compliance on PI}

A comparison of the PI under the same condition and length, but various combinations of vessel compliances showed some difficulties in drawing a correlation, similar to the case mentioned above. In distal tubes, the PI showed no significant changes based on the tube compliances; however, in proximal tubes, higher compliances resulted in a higher PI rather than a lower tube compliance (Fig. $3 E, F)$. Such an observation can also be inferred by a qualitative analysis of the Doppler waveform, based on the fact that pulsatile waveforms were detected when the proximal vessel compliance was higher.

\section{Influence of vessel compliance on AT and Al in the early systole}

There were no patterns of tendencies when distal and proximal tube compliances were compared, but the Al decreased with a greater length of both proximal and distal tubes.

Table 2. Summary of Doppler examinations for different distal resistances

\begin{tabular}{|c|c|c|c|c|c|c|c|c|}
\hline $\begin{array}{c}\text { Proximal } \\
\text { compliance level }\end{array}$ & $\begin{array}{c}\text { Distal } \\
\text { compliance level }\end{array}$ & $\begin{array}{l}\text { Grade of } \\
\text { stenosis }\end{array}$ & Stopcock & PSV (cm/sec) & $\operatorname{MDV}(\mathrm{cm} / \mathrm{sec})$ & $\mathrm{RI}$ & $\mathrm{PI}$ & $\mathrm{Al}\left(\mathrm{cm} / \mathrm{sec}^{2}\right)$ \\
\hline $2 \mathrm{H}$ & $2 \mathrm{H}$ & G0 & Open & 227.3 & 6.7 & 0.97 & 2.91 & $1,460.7$ \\
\hline $2 \mathrm{H}$ & $2 \mathrm{H}$ & G0 & $30^{\prime}$ & 310.1 & -18.7 & 1.06 & 5.75 & $1,715.6$ \\
\hline $2 \mathrm{H}$ & $2 \mathrm{H}$ & G0 & $60^{\prime}$ & 262.0 & -16.0 & 1.06 & 5.94 & $2,211.8$ \\
\hline $2 \mathrm{H}$ & $2 \mathrm{~L}$ & G0 & Open & 169.5 & 50.0 & 0.71 & 1.05 & $1,034.9$ \\
\hline $2 \mathrm{H}$ & $2 \mathrm{~L}$ & Go & $30^{\prime}$ & 169.5 & 26.8 & 0.84 & 1.50 & $1,249.0$ \\
\hline $2 \mathrm{H}$ & $2 \mathrm{~L}$ & Go & $60^{\prime}$ & 146.3 & 7.1 & 0.95 & 2.17 & 912.0 \\
\hline $2 \mathrm{~L}$ & $2 \mathrm{~L}$ & G0 & Open & 272.7 & 53.5 & 0.80 & 1.80 & $1,890.5$ \\
\hline $2 \mathrm{~L}$ & $2 \mathrm{~L}$ & Go & $30^{\prime}$ & 234.5 & -12.7 & 1.05 & 4.47 & $1,761.2$ \\
\hline $2 \mathrm{~L}$ & $2 \mathrm{~L}$ & G0 & $60^{\prime}$ & 229.4 & -22.9 & 1.10 & 5.61 & $2,326.0$ \\
\hline $2 \mathrm{H}$ & $2 \mathrm{H}$ & G2 (1.5) & Open & 205.9 & 18.7 & 0.91 & 2.15 & $1,203.1$ \\
\hline $2 \mathrm{H}$ & $2 \mathrm{H}$ & G2 (1.5) & $30^{\prime}$ & 227.3 & 1.9 & 0.99 & 3.59 & $1,579.9$ \\
\hline $2 \mathrm{H}$ & $2 \mathrm{H}$ & G2 (1.5) & $60^{\prime}$ & 181.8 & -2.7 & 1.01 & 3.56 & $1,737.9$ \\
\hline $2 \mathrm{~L}$ & $2 \mathrm{~L}$ & G2 (1.5) & Open & 305.9 & 45.9 & 0.85 & 1.88 & $2,013.7$ \\
\hline $2 \mathrm{~L}$ & $2 \mathrm{~L}$ & G2 (1.5) & $30^{\prime}$ & 295.7 & 5.1 & 0.98 & 3.77 & $2,294.1$ \\
\hline $2 \mathrm{~L}$ & $2 \mathrm{~L}$ & G2 (1.5) & $60^{\prime}$ & 234.5 & -25.5 & 1.11 & 6.24 & $2,731.1$ \\
\hline $2 \mathrm{H}$ & $2 \mathrm{~L}$ & G2 (1.5) & Open & 201.6 & 41.0 & 0.80 & 1.34 & $1,835.3$ \\
\hline $2 \mathrm{H}$ & $2 \mathrm{~L}$ & G2 (1.5) & $30^{\prime}$ & 224.8 & 14.3 & 0.94 & 2.61 & $1,573.5$ \\
\hline $2 \mathrm{H}$ & $2 \mathrm{~L}$ & G2 (1.5) & $60^{\prime}$ & 187.3 & 1.8 & 0.99 & 4.44 & $1,382.9$ \\
\hline $2 \mathrm{H}$ & $2 \mathrm{~L}$ & G3 (1.5) & Open & 174.9 & 48.2 & 0.72 & 1.13 & $1,052.7$ \\
\hline $2 \mathrm{H}$ & $2 \mathrm{~L}$ & G3 (1.5) & $30^{\prime}$ & 182.0 & 21.4 & 0.88 & 1.82 & $1,315.9$ \\
\hline $2 \mathrm{H}$ & $2 \mathrm{~L}$ & G3 (1.5) & $60^{\prime}$ & 167.7 & 16.1 & 0.90 & 2.32 & $1,300.0$ \\
\hline $2 \mathrm{H}$ & $2 \mathrm{H}$ & G3 (1.5) & Open & 199.8 & 66.0 & 0.67 & 1.24 & $1,149.9$ \\
\hline $2 \mathrm{H}$ & $2 \mathrm{H}$ & G3 (1.5) & $30^{\prime}$ & 205.2 & 46.4 & 0.77 & 1.52 & $1,586.0$ \\
\hline $2 \mathrm{H}$ & $2 \mathrm{H}$ & G3 (1.5) & $60^{\prime}$ & 196.3 & 28.5 & 0.85 & 1.90 & $1,903.2$ \\
\hline $2 \mathrm{~L}$ & $2 \mathrm{~L}$ & G3 (1.5) & Open & 232.0 & 30.6 & 0.87 & 1.68 & $1,598.2$ \\
\hline $2 \mathrm{~L}$ & $2 \mathrm{~L}$ & G3 (1.5) & $30^{\prime}$ & 224.3 & 33.1 & 0.85 & 2.28 & $1,733.3$ \\
\hline $2 \mathrm{~L}$ & $2 \mathrm{~L}$ & G3 (1.5) & $60^{\prime}$ & 201.4 & 7.6 & 0.96 & 3.45 & $2,600.0$ \\
\hline
\end{tabular}

"L" indicates a polyethylene tube, and " $\mathrm{H}$ " indicates a rubber tube. $2 \mathrm{~L}$ indicates a polyethylene tube of 2-m length, and $2 \mathrm{H}$ indicates a rubber tube of $2-\mathrm{m}$ length. 1.5 in parentheses indicates the length of a stenotic segment of $1.5 \mathrm{~cm}$ in each grade.

PSV, peak systolic velocity; MDV, minimum diastolic velocity; RI, resistive index; PI, pulsatility index; Al, acceleration index. 
Influence of the Resistance Change in the Vessels Distal to the Doppler Sonography Examination Site

The measurements are summarized in Table 2. An increase in the resistance of the tubes distal to the Doppler examination site resulted in a slight decrease in the PSV, without any statistical significance (Fig. 4). In contrast, the MDV decreased more clearly than the PSV, even resulting in a reversal; therefore, both the RI and $\mathrm{PI}$ increased with an increase in the distal resistance $(P<0.05)$. Despite contradicting results, the $\mathrm{Al}$ tended to increase when the distal resistance increased.

Influence of the Resistance Change in the Vessels Proximal to the Doppler Sonography Examination Site

The PSV tends to decrease with increasing proximal stenosis.
Although there was no noticeable decrease in mild stenosis, it dramatically decreased at a certain threshold (Fig. 5A). Compared to relatively hard polyethylene tubes, rubber tube models demonstrated the pulsus parvus phenomenon more clearly due to lower PSV values. There was no meaningful difference in the PSV between different lengths of stenosis (i.e., $1.5 \mathrm{~cm}$ vs. $3 \mathrm{~cm}$ ). Stenosis in the proximal part resulted in relatively low minor changes in the MDV, as compared to the PSV; therefore, the $\mathrm{RI}, \mathrm{Pl}$, and $\mathrm{Al}$ decreased as well. The RI was maintained up to a certain level, yet it dramatically decreased in the significant pulsus parvus (Fig. 5B). The polyethylene tube models, with less elasticity, represented a pulsus parvus wave in grade 4, whereas the more elastic rubber tubes demonstrated the same phenomenon between grade 2 and grade 3 stenosis models. In the rubber tube models, the pulsus parvus was observed in grade

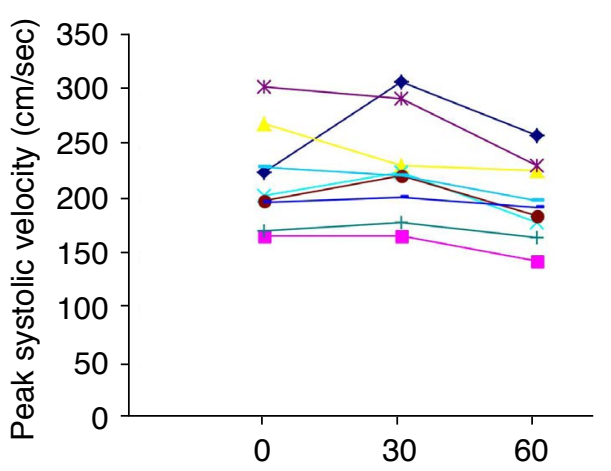

A

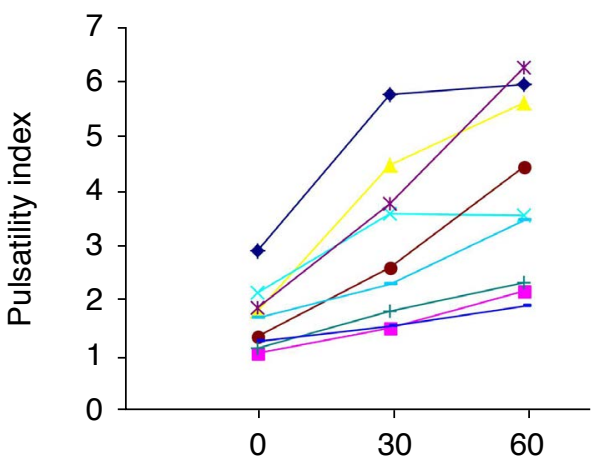

D

Fig. 4. Effect of distal resistance.

A-E. Each graph shows the comparison of peak systolic velocity (A), minimum diastolic velocity (B), resistive index (C), pulsatility index (D), and acceleration index (E) for different distal resistance. Each numeric $(0,30$ and 60$)$ on the $X$-axis represents the degree of locking of distal stopcock. Each line on the graphs represents the changes of the several parameters according to different distal resistance. The measurements are summarized in Table 2. When the resistance of the tubes distal to the Doppler examination site increased, the peak systolic velocity decreased slightly, however, without a particular difference. In contrast, the minimum diastolic velocity decreased more clearly than the peak systolic velocity, even resulting in a reversal, so that both the resistive index and pulsatility index increased with an increase in the distal resistance. 2L, polyethylene tube of 2-m length; $2 \mathrm{H}$, rubber tube of 2-m length; GO, G2 and G3, grade of stenosis of 1.5-cm segment.

e-ultrasonography.org

Ultrasonography 36(1), January 2017

47 
3 when the stenosis length was $1.5 \mathrm{~cm}$. In contrast, it was observed in grade 2 when the stenosis length was $3 \mathrm{~cm}$. With the presence of proximal stenosis, a reduction of the $\mathrm{Al}$ as well as pulsus parvus in response to a reduction in the PSV was demonstrated. However, no correlation between the degree of stenosis and AT, defined as time to reach the early systolic peak, was observed. When a greater resistance was applied on the distal part, the PSV and MDV fell while the RI and Al increased; this made it more difficult to diagnose vascular stenosis in the proximal part, as compared to a case where the distal part was subjected to a lower resistance.

\section{Influence due to Changes in the Pulse Rate}

The pulse rate decreased with a prolonged delay of the diastole. The PSV fluctuated in various ways as the pulse rate decreased; however, the MDV steadily decreased. Accordingly, the RI, PI, and AT increased as the pulse rate decreased due to the prolonged diastolic transit time $(P<0.05)$ (Table 3, Fig. 6).

\section{Discussion}

One of the characteristics of the vascular system is that the blood vessels have the ability to be dilated; i.e., the system possesses

Table 3. Summary of Doppler examinations for different diastolic transit time (pulse rate)

\begin{tabular}{|c|c|c|c|c|c|c|c|c|}
\hline $\begin{array}{c}\text { Proximal } \\
\text { compliance level }\end{array}$ & $\begin{array}{c}\text { Distal } \\
\text { compliance level }\end{array}$ & Stopcock & $\begin{array}{l}\text { Diastolic transit } \\
\text { time (msec) }\end{array}$ & PSV $(\mathrm{cm} / \mathrm{sec})$ & $\mathrm{MDV}(\mathrm{cm} / \mathrm{sec})$ & $\mathrm{RI}$ & $\mathrm{PI}$ & $\mathrm{Al}\left(\mathrm{cm} / \mathrm{sec}^{2}\right)$ \\
\hline $2 \mathrm{~L}$ & $2 \mathrm{~L}$ & Open & 0 & 336.0 & 98.1 & 0.71 & 1.14 & $1,946.5$ \\
\hline $2 \mathrm{~L}$ & $2 \mathrm{~L}$ & Open & 10 & 327.1 & 89.2 & 0.73 & 1.23 & $2,052.0$ \\
\hline $2 \mathrm{~L}$ & $2 \mathrm{~L}$ & Open & 30 & 371.7 & 62.5 & 0.83 & 1.78 & $2,379.1$ \\
\hline $2 \mathrm{~L}$ & $2 \mathrm{~L}$ & Open & 50 & 339.0 & 53.5 & 0.84 & 2.21 & $3,039.9$ \\
\hline $2 \mathrm{~L}$ & $2 \mathrm{~L}$ & Open & 70 & 350.9 & 35.7 & 0.90 & 2.62 & $2,478.3$ \\
\hline $2 \mathrm{~L}$ & $2 \mathrm{~L}$ & Open & 90 & 333.1 & 32.7 & 0.90 & 2.90 & $2,622.4$ \\
\hline $2 \mathrm{~L}$ & $2 \mathrm{~L}$ & Open & 110 & 345.0 & 20.8 & 0.94 & 3.19 & $2,541.3$ \\
\hline $2 \mathrm{~L}$ & $2 \mathrm{~L}$ & Open & 200 & 347.9 & 11.9 & 0.97 & 3.25 & $3,370.3$ \\
\hline
\end{tabular}

$2 \mathrm{~L}$ indicates a polyethylene tube of 2-m length.

PSV, peak systolic velocity; MDV, minimum diastolic velocity; RI, resistive index; PI, pulsatility index; Al, acceleration index.
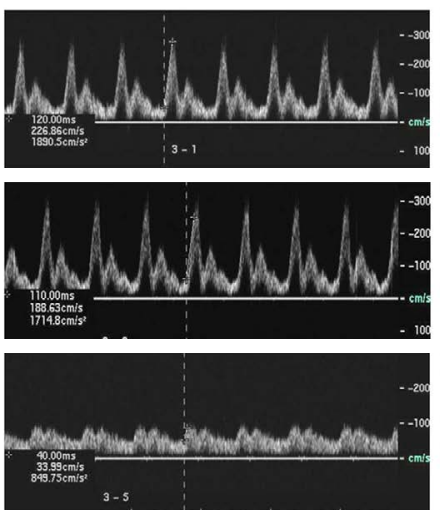

A
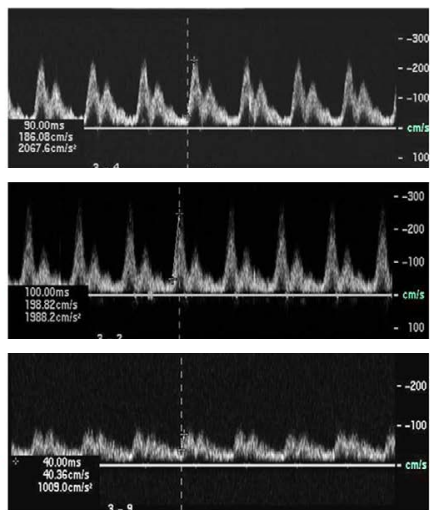

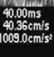

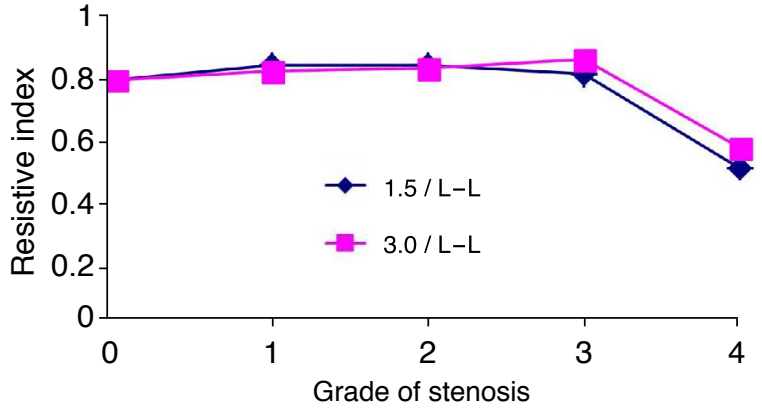

B

Fig. 5. Spectral Doppler waveforms (A) and a graph (B) of the resistive index in the stenosis model.

A. Doppler waveforms are numbered sequentially from the lowest (left, top) to the highest (left, bottom) degree of the stenosis in the lowcompliance setting (2L-2L): grade 0 (left, top); grade 1 (right, top), grade 2 (left, middle); grade 3 (right, middle); grade 4 (left, bottom). The last Doppler tracing was obtained in the high-compliance model $(2 \mathrm{H}-2 \mathrm{H})$ with grade 4 stenosis. Pulsus parvus patterns are noted in grade 4 of both compliance settings (bottom). "L" represents the low-compliance tube (polyethylene tube). "H" represents the high-compliance tube (rubber tube). B. Each symbol represents a different length of the stenotic segment $(1.5 \mathrm{~cm}$ or $3 \mathrm{~cm})$. The resistive index is abruptly decreased at grade 4 in each length of the stenotic segment. There was no difference in the resistive index according to the length of the stenotic segment. 
distensibility. Such distensibility plays an important role in the circulation; e.g., the artery's distensibility adjusts the output of the heartbeat and provides an averaging effect so that the consistent and continual blood flow can reach the very small vessels at the very end of the tissues. However, hemodynamically, the capacity of the vessels to reserve the blood depending on the increase in the blood pressure has more significance than the distensibility itself. The increase in the volume dependent on the increase in the blood pressure is usually defined as the blood vessel compliance, or

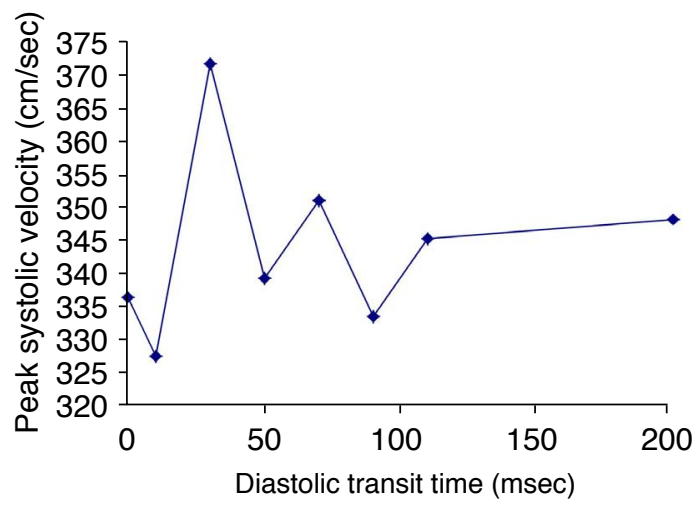

A

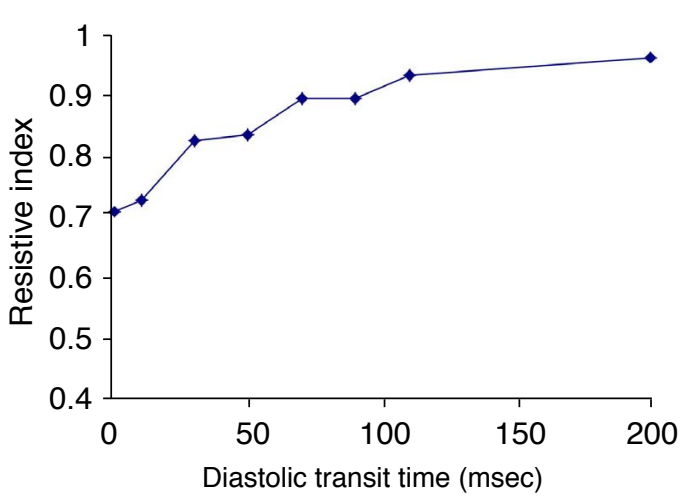

C

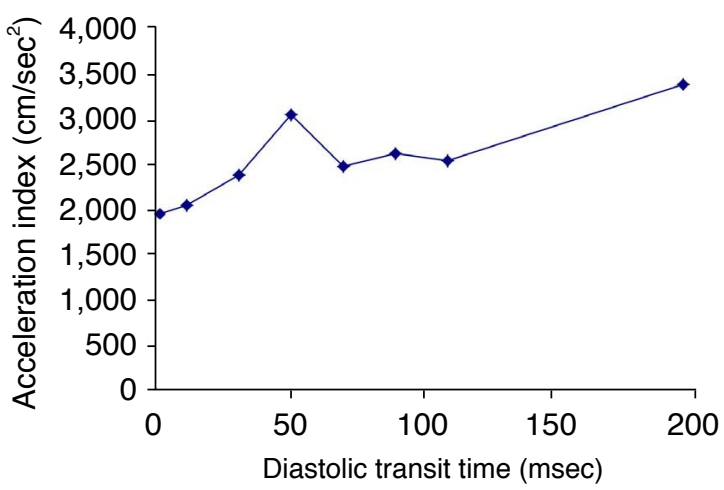

$E$ capacitance. We used two types of tubes with three different lengths in the vascular phantom to evaluate the influence of compliance on the Doppler waveform. Rubber tubes with high compliance were used for simulating the compliance of human blood vessels, and tubes made of polyvinylchloride resin, which have lower compliance than the rubber tubes, replaced the rubber tubes in order to induce change and observe the influence of changes in compliance on arterial Doppler waveforms.

The relatively consistent waveforms observed in the case of the

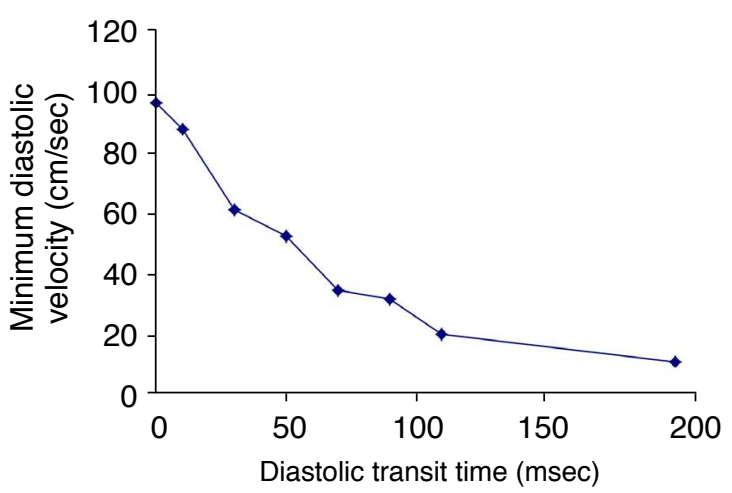

B

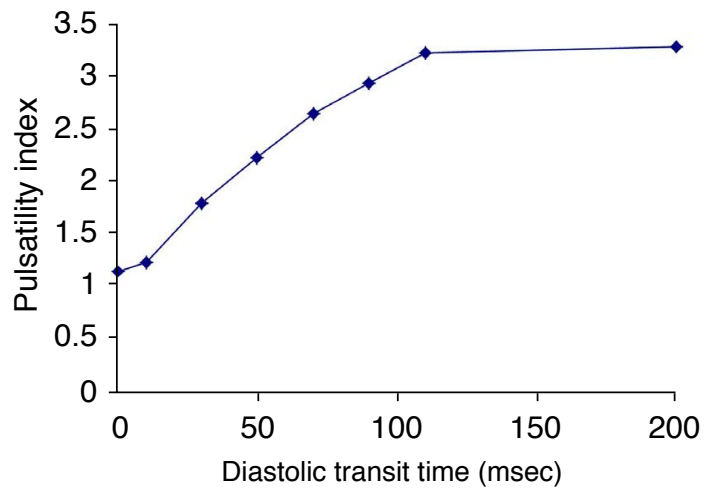

D

Fig. 6. Effect of pulse rate.

A-E. Each graph shows the comparison of peak systolic velocity (A), minimum diastolic velocity (B), resistive index (C), pulsatility index (D), and acceleration index (E) for different diastolic transit time (msec). The peak systolic velocity fluctuated in various ways as the pulse rate decreased; however, the minimum diastolic velocity steadily decreased. Accordingly, the resistive index, pulsatility index, and acceleration time increased as the pulse rate decreased due to the prolonged diastolic transit time. 
tubes with very low compliance can be explained by the transmitted pulses. In contrast, when the tubes proximal and distal to the examination site were replaced with higher compliance tubes, the waveforms changed into more complex and various forms. This can be explained by the temporary reservation of the kinetic energy that originated from the systolic pressure pulse in the form of potential energy that was exerted due to compliance at the end of systolic phase when the blood pressure decreased. Therefore, the early systolic peak of the Doppler waveforms can be explained by the first transmitted pulse, and the second peak that forms more broadly in the systolic phase can be caused by the vessel compliance. The proximal vessel compliance plays a crucial role in the formation of the second peak after the early-systole peak. Further, the compliance peak was influenced by the resistance of the distal area, in which with the low distal resistance, the blood flow caused by the compliance was sent to the distal area to prolong the systolic blood flow while the blood volume increased in the diastolic phase. In the case of a high resistance in the distal area, the energy reserved via compliance could reverse the blood flow. Therefore, the complex Doppler waveforms that cannot be explained by the compliance in the proximal area were possibly influenced by the compliance of the distal area, and the resistance factor.

Although the compliance of proximal or distal tubes influences changes in Doppler waveforms, this experiment did not show any consistent tendency of the effect of compliance on the changes in the PSV, RI, PI, AT, and AI. In this study, the compliance and resistance in both proximal and distal areas were manipulated to determine an effect; however, within human bodies, the resistance can change from 0 to infinity but not the vascular compliance. Analogous to a spring, within the limit of the spring, the compliance remains the same irrespective of the amount of increase. Even though the vessels are regulated by the autonomous nervous system that controls the smooth muscles, the blood vessels within a certain area have the same compliance irrespective of the amount of increase. The hardening of the arteries or the swelling of the interstitium, cellular infiltration, etc., can influence the compliance of the vessels; however, compliance does not have the property of dynamic change like the resistance, and cannot be changed drastically. Therefore, while the blood waveforms are usually influenced by the pressure waves, and the proximal and distal resistances, the vessel compliance does not change significantly, which cannot constitute the main influential factor, but a dependent variable.

Bude and Rubin [16] showed that in the case where there is no compliance, that there was no correlation between the resistance and Rl; Tublin et al. [17] reported that even in the case of a strong increase in the resistance by injecting phenylephrine in an in vivo rabbit experiment, the RI increased insignificantly. In the experiment with polyethylene tubes that minimalized the compliance, the RI changed as the distal resistance increased or the length of the tube changed. With very low compliance, proximal Doppler waveforms were not attenuated but delivered until the distal area, so that the RI between the proximal and the distal areas remained about the same. However, the resistance of the vessels attenuates the Doppler waveforms so that the blood flow changes from a pulsatile to a continual non-pulsatile flow (i.e., the RI is 0 ), which results in a change in the RI values. The distal resistance increase influenced the RI by changing the velocity of the systole and the diastole with varying ratios. This study showed that the MDV decreased more clearly than the PSV, even resulting in a reversal, so that the RI and the PI both increased with an increase in the distal resistance. Therefore, the changes in the distal vessel resistance significantly influence the changes in the RI. In contrast, Tublin et al. reported little effect on the RI despite the rapid change in renal vessel resistance suggesting the influence of a vasoconstrictor cannot be limited to the resistance in the proximal or distal area [17]. The vasoconstrictor constricts not only distal vessels but also the other vessels simultaneously; moreover, it influences other factors such as the heart rate.

For the diagnosis of renal artery stenosis, an early Doppler test directly examined the stenotic segment of renal arteries, yet favorable results were not demonstrated because of technical difficulties to implement the test as well as a high likelihood of false-negative or false-positive. Multiple studies reported that renal vascular stenosis might be diagnosed via small systolic wave and delayed systolic acceleration (known as PTP) $[18,19]$; peripheral arteries in kidneys were examined using the Doppler test instead of stenotic arteries. As the stenosis worsened reflecting the resistance in the proximal blood vessels, the PSV on the sonogram site dramatically decreased to a certain degree. In contrast, the MDV showed relatively small changes and induced a reduction in the RI. The Pl and Al tend to lower with an increase in the degree of stenosis. A longer stenosis part indicates the greater degree of stenosis and increased resistance in the proximal part. With longer stenosis, therefore, clear PTP formation was demonstrated despite a low degree of stenosis. Despite the significance of stenosis in the formation of PTP, it was also demonstrated at a lower degree of stenosis when the compliance of blood vessels was greater. Therefore, a more accurate diagnosis might be achieved if compliance or factors impacting compliance are taken into consideration in a case where PTP was utilized as a surrogate marker to predict proximal vascular stenosis. In the presence of proximal stenosis, the systolic $\mathrm{Al}$ and $\mathrm{RI}$ increased in response to the increased resistance on distal blood vessels, thereby masking 
the formation of PTP. Therefore, the formation of PTP might be contrasted with lesser resistance on distal blood vessels, thus facilitating a diagnosis of a lower degree of stenosis. Rene et al. [20] reported that diagnostic sensitivity for renal artery stenosis could be improved by administrating captopril to achieve a reduction in the renal vascular resistance and maximize the formation of PTP.

In addition to resistance or compliance, renal arterial Doppler waveforms are influenced by various non-renal factors such as cardiac function, and anatomical structure of the blood vessels [13]. Cardiac functions affecting waveforms include systolic and diastolic pressure or time, pulse pressure, cardiac output, pulse rate, and others. Since these factors are profoundly associated, it is difficult to analyze them independently. The pulse rate decreased when the delay rate was prolonged when other controlled variables of the artificial were fixed. With decreased pulse rate, several parameters, specifically, the RI, PI, and Al, were increased. Mostbeck et al. [21] reported that a significant correlation was found between the RI and the heart rate. Since the body's compensatory responses serve to maintain a normal blood flow volume or blood pressure as the pulse rate decreases. When the pulse rate increases, the PSV remains almost the same while the $\mathrm{RI}$ is decreased with an increase in the EDV as the systole takes place without a sufficient period of diastole.

A limitation of our study concerns the difference in the compliance of the renal arteries in the human body and tubes in the phantom model. The range or volatility of compliance of two types of tubes in the phantom is wide and narrow, and the tube exchange only represents the increased or decreased compliance. Further, the tube length is far from reality. However, they reflect the effect of compliance on the Doppler waveform. Experimental models using animals are not suitable for the evaluation of the effect of vascular compliance because of the narrow range of alteration and difficulty in making changes to the compliance. Our phantom model mimics a kidney model and does not reflect the autoregulatory ability of the kidney. However, our experimental work in vitro showed considerable value in the interpretation of the effects of various variables on Doppler waveforms and would avoid some elements of uncertainty in the direction and magnitude of the changes in compliance or resistance.

On the basis of this research, it was possible to construct a mock renal blood flow model with low resistance, which facilitated the analysis of arterial Doppler waveforms in the renal blood flow, and evaluation of the factors that influenced the waveforms. The research showed that spectral Doppler waveforms of the artificial renal blood flow are influenced by many variables including vascular compliance and resistance. There was correlation between the distal resistance and $\mathrm{RI}$, while there was no consistent tendency of the influence of the compliance on the changes in the PSV, RI, PI, AT, and Al. Without the changes in intrinsic factors such as compliance or resistance, the changes in the pulse rate showed an influence on the RI as an extrinsic factor. With decreased pulse rate, several parameters, specifically, the $\mathrm{RI}, \mathrm{Pl}$, and $\mathrm{Al}$, are increased. This research can help in providing fundamental information necessary in other experiments on Doppler waveforms and its application in the clinical studies.

ORCID: Chang Kyu Sung: http://orcid.org/0000-0003-4922-5107; Kyoung Ho Lee: http://orcid.org/0000-0001-6045-765X; Seung Hyup Kim: http://orcid.org/00000002-9339-5907

\section{Conflict of Interest}

No potential conflict of interest relevant to this article was reported.

\section{Supplementary Material}

Supplementary Table 1. Summary of Doppler examinations for various combinations of compliance and tube length (https://doi. org/10.14366/usg.15055).

\section{References}

1. Platt JF, Rubin JM, Ellis JH, DiPietro MA. Duplex Doppler US of the kidney: differentiation of obstructive from nonobstructive dilatation. Radiology 1989;171:515-517.

2. Platt JF, Ellis JH, Rubin JM, DiPietro MA, Sedman AB. Intrarenal arterial Doppler sonography in patients with nonobstructive renal disease: correlation of resistive index with biopsy findings. AJR Am J Roentgenol 1990;154:1223-1227.

3. Platt JF, Rubin JM, Ellis JH. Acute renal failure: possible role of duplex Doppler US in distinction between acute prerenal failure and acute tubular necrosis. Radiology 1991;179:419-423.

4. Kim SH, Kim WH, Choi BI, Kim CW. Duplex Doppler US in patients with medical renal disease: resistive index vs serum creatinine level. Clin Radiol 1992;45:85-87.

5. Bige N, Levy PP, Callard P, Faintuch JM, Chigot V, Jousselin V, et al. Renal arterial resistive index is associated with severe histological changes and poor renal outcome during chronic kidney disease. BMC Nephrol 2012;13:139.

6. Crutchley TA, Pearce JD, Craven TE, Stafford JM, Edwards MS, Hansen KJ. Clinical utility of the resistive index in atherosclerotic renovascular disease. J Vasc Surg 2009;49:148-155.

7. Radermacher J, Mengel M, Ellis S, Stuht S, Hiss M, Schwarz A, et al. The renal arterial resistance index and renal allograft survival. $N$ Engl J Med 2003;349:115-124.

8. Chen JH, Pu YS, Liu SP, Chiu TY. Renal hemodynamics in patients with obstructive uropathy evaluated by duplex Doppler sonography. J Urol 1993;150:18-21. 
9. Okten A, Dinc H, Kul M, Kaya G, Can G. Renal duplex Doppler ultrasonography as a predictor of preclinical diabetic nephropathy in children. Acta Radiol 1999;40:246-249.

10. Perrella RR, Duerinckx AJ, Tessler FN, Danovitch GM, Wilkinson A, Gonzalez $S$, et al. Evaluation of renal transplant dysfunction by duplex Doppler sonography: a prospective study and review of the literature. Am J Kidney Dis 1990;15:544-550.

11. Tublin ME, Bude RO, Platt JF. Review. The resistive index in renal Doppler sonography: where do we stand? AJR Am J Roentgenol 2003; 180:885-892.

12. Bude RO, Rubin JM, Platt JF, Fechner KP, Adler RS. Pulsus tardus: its cause and potential limitations in detection of arterial stenosis. Radiology 1994;190:779-784.

13. Krumme B, Hollenbeck M. Doppler sonography in renal artery stenosis: does the Resistive Index predict the success of intervention? Nephrol Dial Transplant 2007;22:692-696.

14. Chung HW, Chung MJ, Park JH, Chung JW, Lee DH, Min BG. A study of Doppler waveform using pulsatile flow model. J Korean Radiol Soc 1997;37:225-232.

15. Weast RC. Handbook of chemistry and physics: a ready-reference book of chemical and physical data. 52nd ed. Cleveland, $\mathrm{OH}$ : Chemical Rubber, 1971;D191-D192.

16. Bude RO, Rubin JM. Relationship between the resistive index and vascular compliance and resistance. Radiology 1999;211:411-417.

17. Tublin ME, Tessler FN, Murphy ME. Correlation between renal vascular resistance, pulse pressure, and the resistive index in isolated perfused rabbit kidneys. Radiology 1999;213:258-264.

18. Handa N, Fukunaga R, Uehara A, Etani $H$, Yoneda S, Kimura $K$, et al. Echo-Doppler velocimeter in the diagnosis of hypertensive patients: the renal artery Doppler technique. Ultrasound Med Biol 1986;12:945-952.

19. Kotval PS. Doppler waveform parvus and tardus: a sign of proximal flow obstruction. J Ultrasound Med 1989;8:435-440.

20. Rene PC, Oliva VL, Bui BT, Froment D, Harel C, Nicolet V, et al. Renal artery stenosis: evaluation of Doppler US after inhibition of angiotensin-converting enzyme with captopril. Radiology 1995; 196:675-679.

21. Mostbeck GH, Gossinger HD, Mallek R, Siostrzonek P, Schneider $B$, Tscholakoff D. Effect of heart rate on Doppler measurements of resistive index in renal arteries. Radiology 1990;175:511-513. 